\title{
Prognostic role of D-dimer for in-hospital and I-year mortality in exacerbations of COPD
}

\author{
This article was published in the following Dove Press journal: \\ International Journal of COPD \\ 31 October 2016 \\ Number of times this article has been viewed
}

\section{Guoping $\mathrm{Hu}^{\prime}$ \\ Yankui Wu ${ }^{2}$ \\ Yumin Zhou ${ }^{3}$ \\ Zelong $\mathrm{Wu}^{\prime}$ \\ Liping Wei' \\ Yuqun Li' \\ GongYong Peng ${ }^{3}$ \\ Weiqiang Liang' \\ Pixin $\operatorname{Ran}^{3}$}

'Department of Respiratory Medicine, The Third Affiliated Hospital of Guangzhou Medical University, Guangzhou, Guangdong, ${ }^{2}$ Department of Respiratory Disease of People's Hospital of Guangxi Zhuang Autonomous Region, Guangxi Zhuang Autonomous Region, ${ }^{3}$ Guangzhou Institute of Respiratory Disease, State Key Lab of Respiratory Disease, The First Affiliated Hospital of Guangzhou Medical University, Guangzhou, Guangdong, People's Republic of China
Correspondence: Pixin Ran Guangzhou Institute of Respiratory Disease, The First Affiliated Hospital, Guangzhou Medical University, I5I Yanjiang Road, Guangzhou, Guangdong, 5 I0I20, People's Republic of China

Tel +862081340482

$\mathrm{Fax}+862081340482$

Email pxran@gzhmc.edu.cn
Background and objective: Serum D-dimer is elevated in respiratory disease. The objective of our study was to investigate the effect of D-dimer on in-hospital and 1-year mortality after acute exacerbations of chronic obstructive pulmonary disease (AECOPD).

Methods: Upon admission, we measured 343 AECOPD patients' serum D-dimer levels and arterial blood gas analysis, and recorded their clinical characteristics. The level of D-dimer that discriminated survivors and non-survivors was determined using a receiver operator curve (ROC). The risk factors for in-hospital mortality were identified through univariate analysis and multiple logistic regression analyses. To evaluate the predictive role of D-dimer for 1-year mortality, univariate and multivariate Cox regression analyses were performed.

Results: In all, 28 patients died, and 315 patients survived in the in-hospital period. The group of dead patients had lower $\mathrm{pH}$ levels $(7.35 \pm 0.11$ vs $7.39 \pm 0.05, P<0.0001)$, higher D-dimer, arterial carbon dioxide tension $\left(\mathrm{PaCO}_{2}\right)$, C-reactive protein (CRP), and blood urea nitrogen (BUN) levels (D-dimer 2,244.9 $\pm 2,310.7$ vs $768.2 \pm 1,078.4 \mu \mathrm{g} / \mathrm{L}, P<0.0001 ; \mathrm{PaCO}_{2}: 58.8 \pm 29.7$ vs $46.1 \pm 27.0 \mathrm{mmHg}, P=0.018$; CRP: $81.5 \pm 66, P=0.001$; BUN: $10.20 \pm 6.87$ vs $6.15 \pm 3.15 \mathrm{mmol} / \mathrm{L}$, $P<0.0001)$, and lower hemoglobin levels $(118.6 \pm 29.4$ vs $128.3 \pm 18.2 \mathrm{~g} / \mathrm{L}, P=0.001)$. The areas under the ROC curves of D-dimer for in-hospital death were 0.748 ( $95 \%$ confidence interval (CI): $0.641-0.854$ ). D-dimer $\geq 985 \mathrm{ng} / \mathrm{L}$ was a risk factor for in-hospital mortality (relative risk $=6.51 ; 95 \%$ CI 3.06-13.83). Multivariate logistic regression analysis also showed that D-dimer $\geq 985 \mathrm{ng} / \mathrm{L}$ and heart failure were independent risk factors for in-hospital mortality. Both univariate and multivariate Cox regression analyses showed that D-dimer $\geq 985 \mathrm{ng} / \mathrm{L}$ was an independent risk factor for 1-year death (hazard ratio (HR) 3.48, 95\% CI 2.07-5.85 for the univariate analysis; and HR 1.96, 95\% CI 1.05-3.65 for the multivariate analysis).

Conclusion: D-dimer was a strong and independent risk factor for in-hospital and 1-year death for AECOPD patients.

Keywords: AECOPD, chronic obstructive pulmonary diseases, D-dimer, mortality, prognosis

\section{Introduction}

Acute exacerbation is a common phenomenon for chronic obstructive pulmonary disease (COPD) patients during the course of their disease. ${ }^{1}$ Acute exacerbations of COPD (AECOPD) impact long-term prognosis and are associated with substantial in-hospital mortality. The most important factors that determine the overall prognosis of COPD are the frequency and severity of exacerbations; $;^{2,3}$ and AECOPD are often companied with respiratory failure. ${ }^{1}$ The blood of most of AECOPD patients is in a hypercoagulable state for hypoxemia and carbon dioxide retention. ${ }^{4-6}$ This state causes the formation of small pulmonary thrombosis and leads to an adverse prognosis. ${ }^{7-9}$ Some clinical evidence shows that hypercoagulable state and thrombosis in the pulmonary vessels can alter the clinical course of patients with COPD, especially 
during the period of acute exacerbations. ${ }^{10}$ The D-dimer is a product of fibrinolysis, which may increase during many illnesses and physiological conditions associated with thrombosis and thrombolysis. ${ }^{11}$ Studies have showed that elevated plasma D-dimer was associated with adverse outcomes, and D-dimer has been recommended as a prognostic factor for these conditions. ${ }^{10,12-17}$ However, there are few prospective studies that have investigated the role of $\mathrm{D}$-dimer in patients with exacerbations of COPD. We therefore performed a prospective study to investigate the role of serum D-dimer in the prediction of in-hospital mortality and all-cause mortality within 1 year in AECOPD patients.

\section{Methods}

\section{Subjects}

We screened all the AECOPD patients admitted to the respiratory medicine department of the Third Affiliated Hospital of Guangzhou Medical University (Guangzhou, People's Republic of China) from November 2012 to November 2014. All subjects had been diagnosed with COPD previously by respiratory doctors. The exclusion criteria were: hospitalization for a reason other than AECOPD, inability or unwillingness to cooperate with the doctors, and not providing spirometry data. We invited all the AECOPD patients to participate in the present study on the first day of admission to the ward. The ethics committee of The Third Affiliated Hospital of Guangzhou Medical University approved the research protocol.

\section{Study design}

Patient demographics, including age, sex, the number of hospitalizations for AECOPD in the previous year, smoking habit, and comorbidities, with a special emphasis on cardiovascular disease, were recorded. Clinical data, such as vital signs and arterial blood gases $(\mathrm{pH}$, arterial carbon dioxide tension $\left(\mathrm{PaCO}_{2}\right)$, arterial oxygen tension $\left(\mathrm{PaO}_{2}\right)$, and arterial oxygen saturation), were examined on admission. We collected the blood samples from each patient at the time of admission to the department of respiratory disease for D-dimer and standard laboratory measurements (creatinine, blood urea nitrogen (BUN), platelets, hemoglobin, hematocrit, fibrinogen, and C-reactive protein (CRP)). The glomerular filtration rate (GFR) was calculated within 24 hours of admission by the simplified modification of diet in renal disease equation. ${ }^{18}$ GFR $<90 \mathrm{~mL} / \mathrm{min} / 1.73 \mathrm{~m}^{2}$ was considered as renal dysfunction. Congestive heart failure was diagnosed on the base of the Chinese guidelines published in 2007 for the diagnosis and management of chronic heart failure. ${ }^{19}$ Attending physicians not involved in this study made the treatment programs according to the Global initiative for chronic Obstructive Lung Disease (GOLD) guidelines. ${ }^{1}$ Patients were followed up with telephone interviews every 3 months for 1 year by the study investigators. Patients with at least one hospitalization for AECOPD in the previous year were considered as frequent exacerbators.

\section{Statistical analysis}

The primary outcomes were in-hospital and all-cause mortality at 1 year. The secondary outcome was the factors associated with in-hospital death. Categorical variables are presented as $\mathrm{n}(\%)$, and normally distributed values are presented as mean \pm standard deviation. Comparisons between groups were made using chi-squared test (for categorical variables) or analysis of variance (for continuous variables). Receiver operator curve analysis was applied to define the minimal optimal D-dimer level that predicted death. Multivariate logistic regression analysis was applied to determine the independent factors of in-hospital death. To evaluate the influence of D-dimer levels on 1-year mortality, we performed Cox regression univariate and multivariate analyses. Significant confounders, including age, sex, current smoking status, the comorbidities of heart failure and renal dysfunction, $\mathrm{pH}, \mathrm{PaO}_{2}, \mathrm{PaCO}_{2}$, and GOLD stage, were evaluated in the Cox regression analyses. Kaplan-Meier survival curves and log-rank tests were used to compare the time to death between those with elevated D-dimer levels and those without. The results are presented as hazard ratios (HRs) with 95\% confidence interval (CI). We analyzed the data using the Stata statistical software package (Version 7.0, Stata Corporation, College Station, TX, USA) and SPSS 13.0 for Windows (SPSS Inc., Chicago, IL, USA).

\section{Results \\ D-dimer and in-hospital mortality}

We evaluated 391 AECOPD patients. However, there were only 343 AECOPD patients included in our study. Figure 1 shows the flow chart of the included participants. Twentyeight subjects experienced in-hospital mortality. Table 1 shows the differences between survivors and non-survivors in the hospital. There were more patients who suffered from renal dysfunction and congestive heart failure in the non-survivor group. Additionally, the non-survivors were significantly older $(80.4 \pm 8.1$ years old $)$ and more hypercapnic $\left(\mathrm{PaCO}_{2}: 58.8 \pm 29.7 \mathrm{mmHg}\right)$ than the survivors $\left(\mathrm{PaCO}_{2}\right.$ : $46.1 \pm 27.0 \mathrm{mmHg}$ and $75.8 \pm 9.9$ years old, respectively). There was no difference in lung function, fibrinogen, platelets, 


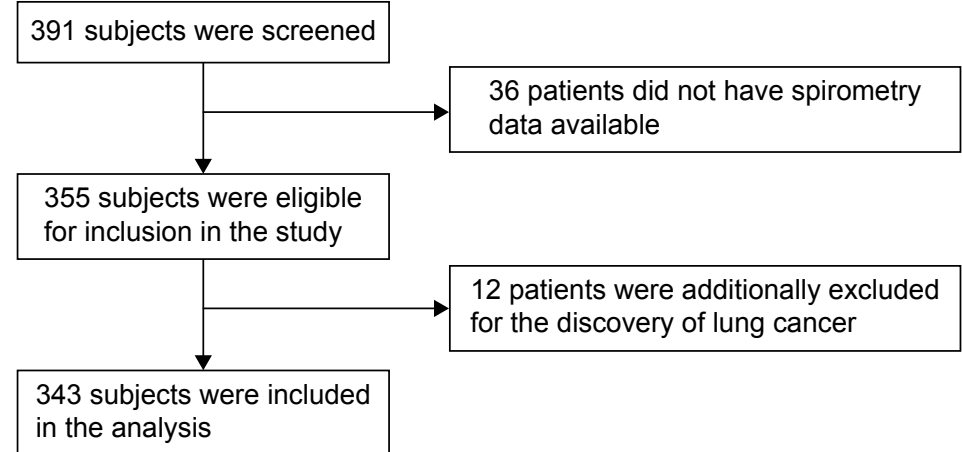

Figure I Flow chart of the study participants.

$\mathrm{PaO}_{2}$, or hematocrit between survivors and those who died. The $\mathrm{pH}$ was significantly lower in the patients who died (pH: 7.346 \pm 0.106 ) compared to survivors ( $\mathrm{pH}: 7.389 \pm 0.054$ ). The plasma levels of D-dimer, CRP, and BUN were higher in non-survivors (D-dimer: 2,244.9 $\pm 2,310.7 \mathrm{ng} / \mathrm{L}, \mathrm{CRP}$ $81.5 \pm 66.0 \mathrm{mg} / \mathrm{L}$, and BUN $10.2 \pm 6.87 \mathrm{mmol} / \mathrm{L}$ ) than in survivors (D-dimer: $768.2 \pm 1,078.4 \mathrm{ng} / \mathrm{L}, \mathrm{CRP}: 42.0 \pm 56.2 \mathrm{mg} / \mathrm{L}$, and BUN: $6.15 \pm 3.15 \mathrm{mmol} / \mathrm{L}$ ).

\section{Associations between Serum D-dimer levels and clinically relevant outcomes}

Figure 2 shows that the area under the curve of serum D-dimer to predict in-hospital death was 0.748 (95\% CI 0.641-0.854), and the cutoff point $985 \mathrm{ng} / \mathrm{L}$, with a sensitivity of 0.714 and a specificity of 0.794 . According to the serum D-dimer levels, the entire cohort was divided into two groups. There were
85 patients with D-dimer levels $\geq 985 \mathrm{ng} / \mathrm{L}$ and 258 with D-dimer levels $<985 \mathrm{ng} / \mathrm{L}$. Table 2 shows non-statistically significant associations of D-dimer levels with sex, $\mathrm{PaCO}_{2}$, $\mathrm{pH}$, fibrinogen, platelets, and $\mathrm{PaO}_{2}(P>0.05)$ and statistically significant associations with age, renal dysfunction, hemoglobin, hematocrit, CRP, and the concentration of creatinine and BUN $(P<0.05)$.

\section{Serum D-dimer levels and in-hospital mortality}

Univariate analyses (Table 3 ) showed that a $\mathrm{pH}<7.35$, $\mathrm{PaCO}_{2} \geq 50 \mathrm{mmHg}, \mathrm{PaO}_{2}<60 \mathrm{mmHg}$, congestive heart failure, renal dysfunction, and D-dimer $\geq 985 \mathrm{ng} / \mathrm{L}$ were risk factors of in-hospital mortality, while age, GOLD stage, sex, and frequent exacerbators in the past year were not risk factors for in-hospital mortality. However, multivariate logistic

Table I Baseline characteristics and survival of patients hospitalized with AECOPD

\begin{tabular}{|c|c|c|c|c|}
\hline Patients characteristics & Alive (3I5) & Dead (28) & $F / X^{2}$ & $P$-value \\
\hline Age & $75.8 \pm 9.9$ & $80.4 \pm 8.1$ & 5.688 & 0.018 \\
\hline Gender (male/female) & $203 / 112$ & $20 / 8$ & 0.551 & 0.458 \\
\hline Smoker (no/ever/yes) & $97 / 172 / 46$ & $10 / 13 / 5$ & 0.701 & 0.704 \\
\hline Malignancy (yes/no) & $18 / 297$ & $3 / 25$ & 1.118 & 0.240 \\
\hline$\% F E V_{1}$ & $51.6 \pm 20.9$ & $52.0 \pm 16.2$ & 0.008 & 0.929 \\
\hline CHF (no/yes) & $270 / 45$ & $13 / 15$ & 27.498 & $<0.0001$ \\
\hline RD (no/yes) & $285 / 29$ & $16 / 12$ & 27.542 & $<0.0001$ \\
\hline $\mathrm{PaCO}_{2}(\mathrm{mmHg})$ & $46.1 \pm 27.0$ & $58.8 \pm 29.7$ & 5.657 & 0.018 \\
\hline $\mathrm{PaO}_{2}(\mathrm{mmHg})$ & $85.4 \pm 41.9$ & $75.5 \pm 25.0$ & 1.5 & 0.221 \\
\hline $\mathrm{pH}$ & $7.389 \pm 0.054$ & $7.346 \pm 0.106$ & 13.597 & $<0.000$ I \\
\hline D-dimer (ng/L) & $768.2 \pm I, 078.4$ & $2,244.9 \pm 2,310.7$ & 37.545 & $<0.0001$ \\
\hline Creatinine $(\mu \mathrm{mmol} / \mathrm{L})$ & $88.8 I \pm 45.63$ & $100.43 \pm 53.26$ & 1.619 & 0.204 \\
\hline BUN (mmol/L) & $6.15 \pm 3.15$ & $10.20 \pm 6.87$ & 32.705 & $<0.0001$ \\
\hline $\mathrm{CRP}(\mathrm{mg} / \mathrm{L})$ & $42.0 \pm 56.2$ & $81.5 \pm 66.0$ & $|2.27|$ & 0.001 \\
\hline Blood platelet $\left(10^{-9} / \mathrm{L}\right)$ & $226.1 \pm 74.1$ & $221.8 \pm 86.3$ & 0.083 & 0.773 \\
\hline Hemoglobin (g/L) & $128.3 \pm 18.2$ & $118.6 \pm 29.4$ & 6.544 & 0.011 \\
\hline Hematocrit (\%) & $39.2 \pm 5.2$ & $37.5 \pm 8.6$ & 2.375 & 0.124 \\
\hline Fibrinogen (g/L) & $3.7 I \pm I .09$ & $3.91 \pm 1.38$ & 0.845 & 0.359 \\
\hline
\end{tabular}

Note: Italics indicate significance.

Abbreviations: AECOPD, acute exacerbations of chronic obstructive pulmonary disease; BUN, blood urea nitrogen; CHF, congestive heart failure; CRP, C-reactive protein; $\mathrm{PaO}_{2}$, arterial oxygen tension; $\mathrm{PaCO}_{2}$, arterial carbon dioxide tension; $\mathrm{RD}$, renal dysfunction. 


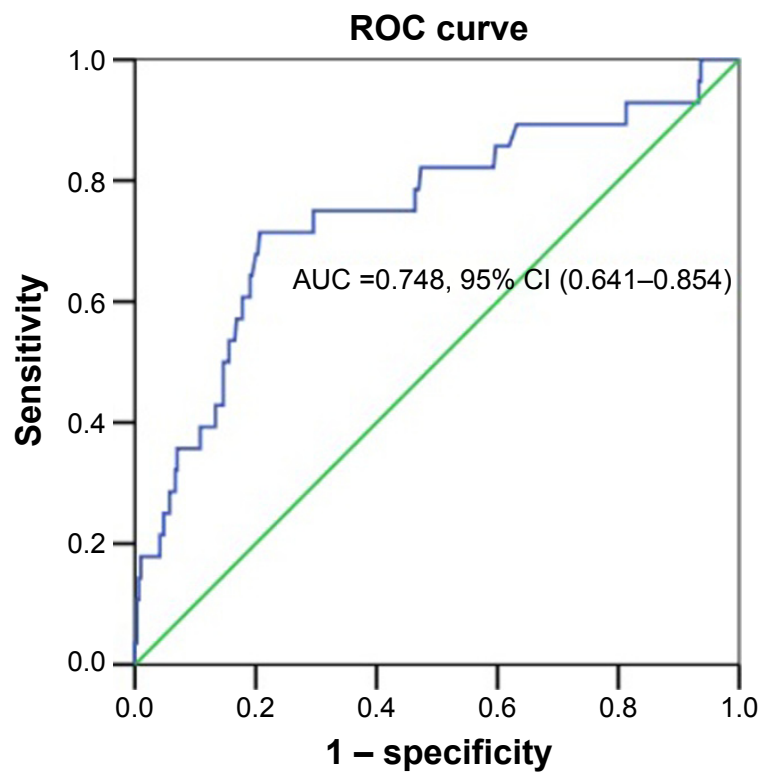

Figure 2 A ROC curve of plasma D-dimer as an overall predictor of death in AECOPD patients

Abbreviations: AECOPD, acute exacerbations of chronic obstructive pulmonary disease; AUC, area under receiver operator characteristic curve; $\mathrm{Cl}$, confidence interval; ROC, receiver operator characteristic.

regression analysis only showed that congestive heart failure and D-dimer $\geq 985 \mathrm{ng} / \mathrm{L}$ were associated with in-hospital mortality (Table 4).

\section{Serum D-dimer levels and I-year mortality}

Fifty-seven subjects died within 1 year. Figure 3 shows the Kaplan-Meier survival curves, which evaluated the time to death within 1 year based on serum D-dimer levels. Patients with serum D-dimer $\geq 985 \mathrm{ng} / \mathrm{L}$ had an increased risk of 1-year mortality compared to those with serum D-dimer < $985 \mathrm{ng} / \mathrm{L}$. Univariate Cox regression analyses showed that D-dimer was a risk factor for 1-year mortality (HR 3.48, 95\% CI 2.07-5.85; $P=0.001$ ) (Table 5). And multivariate analysis also showed that the serum D-dimer level still was an independent risk factor of 1-year mortality (HR $1.96,95 \%$ CI $1.05-3.65 ; P=0.035)$.

Univariate analyses (Table 5) showed that age, $\mathrm{pH}<7.35$, $\mathrm{PaCO}_{2} \geq 50 \mathrm{mmHg}, \mathrm{PaO}_{2}<60 \mathrm{mmHg}$, congestive heart failure, renal dysfunction, CRP, and D-dimer $\geq 985 \mathrm{ng} / \mathrm{L}$ were risk factors of 1-year death, and GOLD stage, sex, and frequent exacerbators in the past year were not associated with 1-year death. Multivariate analysis confirmed that CRP, congestive heart failure, renal dysfunction, and D-dimer $\geq 985 \mathrm{ng} / \mathrm{L}$ were risk factors of 1 -year death (Table 5).

\section{Discussion}

This study is a comprehensive prospective study reporting the associations between D-dimer levels and in-hospital and 1 -year mortality for COPD exacerbation. In the present study, our result showed that the serum D-dimer level was an independent risk factor for in-hospital death (relative risk $=6.51$, 95\% CI: 3.06-13.83) and 1-year mortality ( $\mathrm{HR}=3.48,95 \%$ CI 2.07-5.85; $P=0.001$ for univariate analysis; and $\mathrm{HR}=1.96$, 95\% CI 1.05-3.65; $P=0.035$ for multivariate analysis) for AECOPD. Many studies have reported that the D-dimer was an independent predictor for cardiovascular and all-cause death among elderly persons. ${ }^{10,13,15,20}$ Our study results were consistent with the retrospective study reported by Oren Fruchter, ${ }^{10}$ which showed that D-dimer level examined on

Table 2 Baseline characteristics stratified by the D-dimer concentration

\begin{tabular}{|c|c|c|c|c|}
\hline Patients characteristics & D-dimer $\geq 985(\mu \mathrm{g} / \mathrm{L})$ & D-dimer $<985(\mu \mathrm{g} / \mathrm{L})$ & $F / X^{2}$ & $P$-value \\
\hline Patient & 85 & 258 & & \\
\hline Age & $81.7 \pm 8.0$ & $74.3 \pm 9.7$ & 40.781 & 0.000 \\
\hline Gender (male/female) & $56 / 29$ & $|67 / 9|$ & 0.037 & 0.847 \\
\hline $\mathrm{PaCO}_{2}(\mathrm{mmHg})$ & $48.1 \pm 20.9$ & $46.7 \pm 29.2$ & 0.171 & 0.679 \\
\hline $\mathrm{PaO}_{2}(\mathrm{mmHg})$ & $78.2 \pm 25.8$ & $86.6 \pm 44.4$ & 2.627 & 0.106 \\
\hline $\mathrm{pH}$ & $7.38 \pm 0.09$ & $7.39 \pm 0.05$ & 2.657 & 0.104 \\
\hline CHF (yes/no) & $21 / 64$ & $39 / 219$ & 4.074 & 0.044 \\
\hline RD (yes/no) & $22 / 63$ & $19 / 239$ & 20.832 & 0.000 \\
\hline Hemoglobin & $116.2 \pm 20.8$ & $131.2 \pm 17.5$ & 42.552 & 0.000 \\
\hline Hematocrit & $36.26 \pm 6.06$ & $40.0 \pm 5.09$ & 30.75 & 0.000 \\
\hline CRP & $64.2 \pm 63.7$ & $39.0 \pm 54.7$ & 12.239 & 0.001 \\
\hline Creatinine $(\mu \mathrm{mmol} / \mathrm{L})$ & $100.5 \pm 64.2$ & $86.2 \pm 38.1$ & 6.151 & 0.014 \\
\hline BUN (mmol/L) & $8 .|2 \pm 5.4|$ & $5.94 \pm 2.82$ & 22.890 & 0.000 \\
\hline Fibrinogen & $3.89 \pm 1.27$ & $3.67 \pm 1.05$ & $2.37 I$ & 0.124 \\
\hline Blood platelet & $228.8 \pm 88.4$ & $224.7 \pm 70.2$ & 0.191 & 0.663 \\
\hline
\end{tabular}

Abbreviations: $\mathrm{BUN}$, blood urea nitrogen; $\mathrm{CHF}$, congestive heart failure; $\mathrm{CRP}, \mathrm{C}$-reactive protein; $\mathrm{PaCO}$, arterial carbon dioxide tension; $\mathrm{PaO}$, arterial oxygen tension; $R D$, renal dysfunction. 
Table 3 Hospital-mortality risk in patients with AECOPD

\begin{tabular}{|c|c|c|c|c|c|c|}
\hline Characteristics & Total, $\mathbf{N}$ & Alive, N (\%) & Death, N (\%) & $R R$ & $x^{2}$ & $P$-value \\
\hline Age (years) & & 315 & 28 & & 6.577 & 0.160 \\
\hline$\leq 59$ & 23 & $23(100)$ & $0(4.3)$ & & & \\
\hline $60-69$ & 60 & $57(95.0)$ & $3(5.0)$ & 1 & & \\
\hline $70-79$ & 112 & $105(93.7)$ & $7(6.3)$ & $1.25(0.34-4.66)$ & & \\
\hline $80-89$ & 125 & $110(88.0)$ & $15(12.0)$ & $2.40(0.72-7.97)$ & & \\
\hline$\geq 90$ & 23 & $20(87.0)$ & $3(13.0)$ & $2.61(0.57-12.00)$ & & \\
\hline Smoking & & & & & 0.701 & 0.704 \\
\hline No & 88 & 97 (90.7) & $10(9.3)$ & I & & \\
\hline Yes & 389 & $46(90.2)$ & $5(9.8)$ & $1.05(0.38-2.91)$ & & \\
\hline Ever & & $172(93.0)$ & $13(7.0)$ & $0.75(0.34-1.66)$ & & \\
\hline Sex & & & & & $0.55 \mathrm{I}$ & 0.458 \\
\hline Male & 223 & 203 (9I) & $20(9.0)$ & 1 & & \\
\hline Female & 120 & $112(93.3)$ & $8(6.7)$ & $0.74(0.37-1.64)$ & & \\
\hline pH & & & & & $|5.64|$ & 0.000 \\
\hline$\geq 7.35$ & 281 & $266(94.7)$ & $15(5.3)$ & I & & \\
\hline $7.20-7.35$ & 57 & $46(80.7)$ & II (19.3) & $3.62(1.75-7.46)$ & & \\
\hline$\leq 7.20$ & 5 & $3(60)$ & $2(40)$ & $7.49(2.30-24.4 I)$ & & \\
\hline $\mathrm{PaCO}_{2}(\mathrm{mmHg})$ & & & & & | 4.749 & 0.000 \\
\hline$<50$ & 261 & $248(86.6)$ & $13(5.0)$ & I & & \\
\hline$\geq 50$ & 82 & $67(72)$ & $15(18.3)$ & $3.67(1.82-7.40)$ & & \\
\hline $\mathrm{PaO}_{2}(\mathrm{mmHg})$ & & & & & 13.732 & 0.000 \\
\hline$\geq 60$ & 305 & $286(93.8)$ & $19(6.2)$ & 1 & & \\
\hline$<60$ & 38 & $29(76.3)$ & $9(23.7)$ & $3.89(1.85-7.79)$ & & \\
\hline $\mathrm{CHF}$ & & & & & 27.498 & 0.000 \\
\hline No & 283 & $270(95.4)$ & $13(4.6)$ & I & & \\
\hline Yes & 60 & $45(75)$ & $15(25)$ & $5.44(2.73-10.83)$ & & \\
\hline RD & & & & & 27.667 & 0.000 \\
\hline No & 302 & $286(94.7)$ & $16(5.3)$ & 1 & & \\
\hline Yes & 41 & $29(70.7)$ & $12(29.3)$ & $5.52(2.82-10.84)$ & & \\
\hline D-dimer (mg/L) & & & & & 31.008 & 0.000 \\
\hline$<985$ & 258 & $250(96.9)$ & $8(3.1)$ & I & & \\
\hline$\geq 985$ & 85 & $65(76.5)$ & $20(23.5)$ & $6.51(3.06-13.83)$ & & \\
\hline FEV , predicted & & & & & 2.040 & 0.564 \\
\hline$\geq 80^{\prime}$ & 34 & $34(100)$ & $0(0)$ & & & \\
\hline $50-80$ & 139 & $122(87.8)$ & $17(12.2)$ & I & & \\
\hline $30-50$ & 122 & $113(92.6)$ & $9(7.4)$ & $0.60(0.28-1.30)$ & & \\
\hline$<30$ & 48 & $46(95.8)$ & $2(4.2)$ & $0.34(0.08-1.42)$ & & \\
\hline Frequent exacerbator & & & & & 1.99 & 0.1578 \\
\hline No & 214 & 200 & 14 & I & & \\
\hline Yes & 129 & 115 & 14 & $1.37(0.92-2.04)$ & & \\
\hline
\end{tabular}

Abbreviations: AECOPD, acute exacerbations of chronic obstructive pulmonary disease; $\mathrm{CHF}$, congestive heart failure; $\mathrm{PaCO}$, arterial carbon dioxide tension; $\mathrm{PaO}$, arterial oxygen tension; RD, renal dysfunction; $R R$, relative risk.

admission could be used as a predictive biomarker for shortand long-term mortality for AECOPD. ${ }^{10}$

Several factors have been previously reported to be risk factors for death, including the frequency of AECOPD. ${ }^{21}$ Soler-Cataluna et al have reported that frequent exacerbations were a risk factor for mortality. ${ }^{21}$ However, in the present study, we found that frequent exacerbations were not a risk factor for in-hospital or 1-year mortality. The differing outcomes between studies may be related to the dissimilar definitions of frequent exacerbators. In our study, we could not collect the exact data on the exacerbations in the past year. But, we could collect the previous year's information of hospitalization due to AECOPD; therefore, frequent exacerbators were defined as patients who had at least one hospitalization for AECOPD in the past year. We did find that AECOPD patients with coexisting congestive heart failure had higher 1-year and in-hospital death, which was consistent with previous studies. ${ }^{22,23}$

In our study, we found that elevated CRP was an unfavorable factor for both 1-year and in-hospital death for AECOPD. There are some studies that have reported that elevated HsCRP was a risk factor for adverse outcomes of 
Table 4 Logistic regression analyses of the risk factors associated with hospital mortality in AECOPD patients

\begin{tabular}{|c|c|c|c|c|c|c|c|}
\hline \multirow[t]{2}{*}{ Variable } & \multirow[t]{2}{*}{ B } & \multirow[t]{2}{*}{ SE } & \multirow[t]{2}{*}{ Wald } & \multirow[t]{2}{*}{$P$-value } & \multirow[t]{2}{*}{$\operatorname{Exp}(B)$} & \multicolumn{2}{|c|}{$95 \% \mathrm{Cl}$ for $\operatorname{Exp}(\mathrm{B})$} \\
\hline & & & & & & Lower & Upper \\
\hline D-dimer & 1.685 & 0.503 & 11.218 & 0.001 & 5.395 & 2.012 & 14.465 \\
\hline $\mathrm{PaCO}_{2}(>50 \mathrm{mmHg})$ & 0.983 & 0.608 & 2.618 & 0.106 & 2.673 & 0.812 & 8.794 \\
\hline $\mathrm{PaO}_{2}(<60 \mathrm{mmHg})$ & 0.645 & 0.639 & 1.018 & 0.313 & 1.906 & 0.544 & 6.670 \\
\hline \multicolumn{8}{|l|}{ pH } \\
\hline $\mathrm{pH}(7.20-7.35)$ & 0.617 & 1.411 & 0.191 & 0.662 & 1.853 & 0.117 & 29.444 \\
\hline $\mathrm{pH}(-7.20)$ & 0.572 & 0.613 & 0.871 & 0.351 & 1.773 & 0.533 & 5.899 \\
\hline RD & 0.992 & 0.567 & 3.065 & 0.080 & 2.698 & 0.888 & 8.194 \\
\hline $\mathrm{CHF}$ & 1.715 & 0.504 & 11.564 & 0.001 & 5.555 & 2.068 & 14.924 \\
\hline Constant & -5.149 & 0.604 & 72.594 & 0.000 & 0.006 & & \\
\hline
\end{tabular}

Abbreviations: $\mathrm{AECOPD}$, acute exacerbations of chronic obstructive pulmonary disease; $\mathrm{Cl}$, confidence interval; $\mathrm{CHF}$, congestive heart failure; $\mathrm{PaCO}$, arterial carbon dioxide tension; $\mathrm{PaO}_{2}$, arterial oxygen tension; $\mathrm{RD}$, renal dysfunction; $\mathrm{SE}$, standard error.

AECOPD. ${ }^{24,25}$ Of course, there are also studies that showed that elevated HsCRP was not associated with mortality of AECOPD. ${ }^{26}$ In a previous study from our group, we showed that plasma cystatin $\mathrm{C}$ was a risk factor for in-hospital mortality. ${ }^{27}$ Additionally, in another study from our group, the PSI index was associated with in-hospital death. ${ }^{28} \mathrm{D}$-dimer was an easy-to-obtain biomarker and an independent risk factor of in-hospital and 1-year mortality, which suggest that D-dimer could be used to identify serious patients who need more intensive treatment. So, serum D-dimer levels could be used to construct a multicomponent score in future studies.

Additionally, we also explored the association between D-dimer levels with laboratory tests and clinical characteristics for AECOPD patients. We found that D-dimer levels were higher in patients with renal dysfunction and congestive heart failure and were associated with CRP, hemoglobin, hematocrit, and old age. Alternatively, D-dimer was not

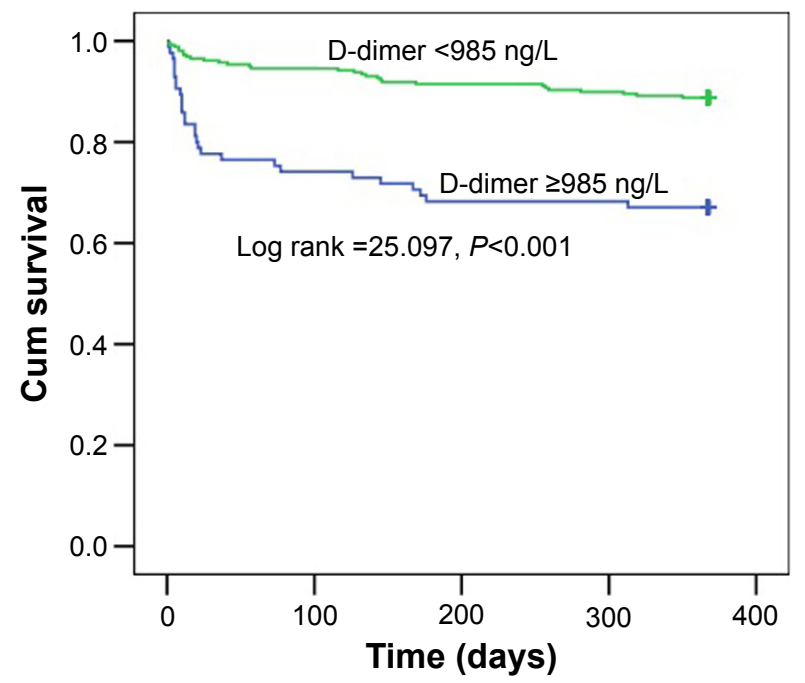

Figure 3 Kaplan-Meier survival curves evaluating the time to death in days for patients with $D$-dimer levels above $(\geq 985 \mathrm{ng} / \mathrm{L})$ and below $(<985 \mathrm{ng} / \mathrm{L})$ the median value ( $P=0.000$ by log-rank test). associated with sex, $\mathrm{PaCO}_{2}, \mathrm{pH}$, fibrinogen, platelets, and $\mathrm{PaO}_{2}$. Ya-Jun Song et al have reported that the serum D-dimer levels significantly negatively related to $\mathrm{PaO}_{2}$ and positively related to $\mathrm{PaCO}_{2}$ in the patients with AECOPD combined with respiratory failure. ${ }^{29}$ There were also some studies that showed D-dimer levels in patients with renal dysfunction were elevated. ${ }^{30,31}$ The study by Jafri et al showed that D-dimer levels in patients with heart failure were higher than patients without heart failure. ${ }^{32}$

Our study has several limitations. The first is that pulmonary embolism, diagnosed by computed tomography pulmonary angiography (CTPA) or pulmonary angiography, was not excluded, which may generate bias. The second limitation is that the patients were followed up only by telephone and every 3 months, which may generate interview bias. The third limitation is that we could not collect the exacerbation times in the past years. The frequent exacerbators were defined as patients with at least one hospitalization for AECOPD in the previous year.

\section{Conclusion}

Conclusively, D-dimer was a risk predictor both for inhospital and 1-year mortality of AECOPD patients. Additionally, the serum D-dimer is a widely and rapidly examined cheaper biomarker, which means that D-dimer could be used to identify serious AECOPD patients.

\section{Acknowledgments}

This study was supported by The National Key Technology R\&D Program of the 12th National Five-year Development Plan 2012BAI05B01 (P.R.), the Medical Science and Technology Research Fund of Guangdong Province (A2016265), and the scientific research fund of the health department of Guangxi Zhuang Autonomous Region (Z2012248). 
Table 5 Univariate and multivariate Cox regression analysis evaluating the effect of serum D-dimer levels and confounders on I-year mortality

\begin{tabular}{|c|c|c|c|c|}
\hline \multirow[t]{2}{*}{ Variable } & \multicolumn{2}{|l|}{ Univariate analysis } & \multicolumn{2}{|c|}{ Multivariate analysis } \\
\hline & HR (95\% CI) & $P$-value & HR (95\% Cl) & $P$-value \\
\hline Age (years) & & 0.019 & & \\
\hline $60-69$ & $2.78(0.34-22.60)$ & 0.339 & $2.34(0.29-19.14)$ & 0.426 \\
\hline 70-79 & $3.01(0.40-22.92)$ & 0.286 & $1.96(0.25-15.42)$ & 0.523 \\
\hline $80-89$ & $5.50(0.75-40.48)$ & 0.094 & $2.55(0.33-19.84)$ & 0.372 \\
\hline$\geq 90$ & $9.65(1.21-77.15)$ & 0.033 & $4.49(0.53-38.07)$ & 0.168 \\
\hline$\% F E V_{1}$ & & 0.608 & & \\
\hline GOLD 2 & $2.24(0.68-7.42)$ & 0.187 & & \\
\hline GOLD 3 & $1.97(0.59-6.63)$ & 0.273 & & \\
\hline GOLD 4 & $2.22(0.60-8.20)$ & 0.232 & & \\
\hline \multicolumn{5}{|l|}{ pH } \\
\hline $7.20-7.35$ & $4.61(1.11-19.13)$ & 0.036 & $1.17(0.2 \mathrm{I}-6.54)$ & 0.858 \\
\hline$\leq 7.20$ & $3.09(1.77-5.40)$ & 0.000 & $1.83(0.90-3.73)$ & 0.096 \\
\hline \multicolumn{5}{|l|}{ Smoker } \\
\hline Yes & $1.01(0.47-2.13)$ & 0.989 & & \\
\hline Ever & $0.70(0.39-1.24)$ & 0.224 & & \\
\hline Gender (male) & $1.18(0.68-2.07)$ & 0.557 & & \\
\hline CHF (no/yes) & $4.53(2.68-7.65)$ & 0.000 & $2.99(1.67-5.36)$ & 0.000 \\
\hline RD (yes) & $4.44(2.54-7.77)$ & 0.000 & $2.21(1.14-4.30)$ & 0.02 \\
\hline $\mathrm{PaCO}_{2}(>50 \mathrm{mmHg})$ & $2.41(1.27-4.09)$ & 0.001 & $1.31(0.64-2.68)$ & 0.456 \\
\hline $\mathrm{PaO}_{2}(<60 \mathrm{mmHg})$ & $2.46(1.30-4.65)$ & 0.006 & $1.67(0.82-3.43)$ & 0.160 \\
\hline D-dimer (>985 $\mu \mathrm{g} / \mathrm{L})$ & $3.48(2.07-5.85)$ & 0.001 & $1.96(1.05-3.65)$ & 0.035 \\
\hline CRP (mg/L) & $1.005(1.001-1.008)$ & 0.017 & $1.004(1.000-1.009)$ & 0.064 \\
\hline AECOPD for the past years (yes) & $1.65(0.98-2.80)$ & 0.058 & $1.38(0.79-2.40)$ & 0.258 \\
\hline
\end{tabular}

Abbreviations: AECOPD, acute exacerbations of chronic obstructive pulmonary disease; CHF, congestive heart failure; Cl, confidence interval; CRP, C-reactive protein; GOLD, Global Initiative for Chronic Obstructive Lung Disease; HR, hazard ratio; $\mathrm{PaO}_{2}$, arterial oxygen tension; $\mathrm{PaCO}$, arterial carbon dioxide tension; RD, renal dysfunction.

\section{Author contributions}

Guoping $\mathrm{Hu}$, Yankui $\mathrm{Wu}$, and Pixin Ran conceived the idea for this report. Guoping Hu, Yankui Wu, and Yumin Zhou wrote the first draft of the article. Guoping Hu, Yankui $\mathrm{Wu}$, Yumin Zhou, GongYong Peng, Zelong Wu, Liping Wei, Yuqun Li, Weiqiang Liang, and Pixin Ran contributed to the final version. Guoping Hu, Zelong Wu, Liping Wei, Yuqun Li, and Weiqiang Liang collected data for the study. Guoping $\mathrm{Hu}$ and Yumin Zhou performed the statistical analyses. Guoping $\mathrm{Hu}$ and Yankui Wu are co-first authors. All authors contributed toward data analysis, drafting and revising the paper and agree to be accountable for all aspects of the work.

\section{Disclosure}

All authors report that there is no potential conflict of interest with any companies/organizations. Yankui $\mathrm{Wu}$ is the wife of Guoping $\mathrm{Hu}$. All the other authors are from a different family.

\section{References}

1. Vestbo J, Hurd SS, Agusti AG, et al. Global strategy for the diagnosis, management, and prevention of chronic obstructive pulmonary disease: GOLD executive summary. Am J Respir Crit Care Med. 2013;187(4): $347-365$.
2. Miravitlles M, Guerrero T, Mayordomo C, Sanchez-Agudo L, Nicolau F, Segu JL. Factors associated with increased risk of exacerbation and hospital admission in a cohort of ambulatory COPD patients: a multiple logistic regression analysis. The EOLO Study Group. Respiration. 2000; 67(5):495-501.

3. Groenewegen KH, Schols AM, Wouters EF. Mortality and mortalityrelated factors after hospitalization for acute exacerbation of COPD. Chest. 2003;124(2):459-467.

4. Macnee W. Pathogenesis of chronic obstructive pulmonary disease. Clin Chest Med. 2007;28(3):479-513, v.

5. Rizkallah J, Man SF, Sin DD. Prevalence of pulmonary embolism in acute exacerbations of COPD: a systematic review and metaanalysis. Chest. 2009;135(3):786-793.

6. Ashitani J, Mukae H, Arimura Y, Matsukura S. Elevated plasma procoagulant and fibrinolytic markers in patients with chronic obstructive pulmonary disease. Intern Med. 2002;41(3):181-185.

7. Lim W, Eikelboom JW, Ginsberg JS. Inherited thrombophilia and pregnancy associated venous thromboembolism. BMJ. 2007;334(7607): 1318-1321.

8. Dahl M, Tybjaerg-Hansen A, Vestbo J, Lange P, Nordestgaard BG. Elevated plasma fibrinogen associated with reduced pulmonary function and increased risk of chronic obstructive pulmonary disease. $\mathrm{Am} J$ Respir Crit Care Med. 2001;164(6):1008-1011.

9. Blom JW, Doggen CJ, Osanto S, Rosendaal FR. Malignancies, prothrombotic mutations, and the risk of venous thrombosis. JAMA. 2005; 293(6):715-722.

10. Fruchter O, Yigla M, Kramer MR. D-dimer as a prognostic biomarker for mortality in chronic obstructive pulmonary disease exacerbation. Am J Med Sci. 2015;349(1):29-35.

11. Haapaniemi E, Tatlisumak T. Is D-dimer helpful in evaluating stroke patients? A systematic review. Acta Neurol Scand. 2009;119: $141-150$. 
12. Guo YJ, Chang MH, Chen PL, Lee YS, Chang YC, Liao YC. Predictive value of plasma (D)-dimer levels for cancer-related stroke: a 3-year retrospective study. J Stroke Cerebrovasc Dis. 2014;23:e249-e254.

13. Hu X, Fang Y, Ye F, et al. Effects of plasma D-dimer levels on early mortality and long-term functional outcome after spontaneous intracerebral hemorrhage. J Clin Neurosci. 2014;21(8):1364-1367.

14. Rodger MA, Le Gal G, Wells P, et al. Clinical decision rules and D-Dimer in venous thromboembolism: current controversies and future research priorities. Thromb Res. 2014;134(4):763-768.

15. Turak O, Canpolat U, Ozcan F, et al. D-dimer level predicts in-hospital mortality in patients with infective endocarditis: a prospective singlecentre study. Thromb Res. 2014;134(3):587-592.

16. Keller K, Beule J, Schulz A, Coldewey M, Dippold W, Balzer JO. D-dimer for risk stratification in haemodynamically stable patients with acute pulmonary embolism. Adv Med Sci. 2015;60(2):204-210.

17. Minami Y, Haruki S, Jujo K, et al. Elevated D-dimer levels predict an adverse outcome in hospitalized patients with acute decompensated heart failure. Int J Cardiol. 2015;204:42-44.

18. Levey AS, Bosch JP, Lewis JB, Greene T, Rogers N, Roth D. A more accurate method to estimate glomerular filtration rate from serum creatinine: a new prediction equation. Modification of Diet in Renal Disease Study Group. Ann Intern Med. 1999;130:461-470.

19. Chinese Society of Cardiology of Chinese Medical A, Editorial Board of Chinese Journal of Cardiology. [Guidelines for the diagnosis and management of chronic heart failure]. Zhonghua Xin Xue Guan Bing Za Zhi. 2007;35(12):1076-1095.

20. Grau E, Tenias JM, Soto MJ, et al. D-dimer levels correlate with mortality in patients with acute pulmonary embolism: Findings from the RIETE registry. Crit Care Med. 2007;35(8):1937-1941.

21. Soler-Cataluna JJ, Martinez-Garcia MA, Roman Sanchez P, Salcedo E, Navarro M, Ochando R. Severe acute exacerbations and mortality in patients with chronic obstructive pulmonary disease. Thorax. 2005; 60(11):925-931.

22. Yoshihisa A, Takiguchi M, Shimizu T, et al. Cardiovascular function and prognosis of patients with heart failure coexistent with chronic obstructive pulmonary disease. J Cardiol. 2014;64(4):256-264.
23. Ahn YH, Lee KS, Park JH, et al. Independent risk factors for mortality in patients with chronic obstructive pulmonary disease who undergo comprehensive cardiac evaluations. Respiration. 2015;90(3):199-205.

24. Karadeniz G, Polat G, Senol G, Buyuksirin M. C-reactive protein measurements as a marker of the severity of chronic obstructive pulmonary disease exacerbations. Inflammation. 2013;36(4):948-953.

25. Man SF, Connett JE, Anthonisen NR, Wise RA, Tashkin DP, Sin DD. C-reactive protein and mortality in mild to moderate chronic obstructive pulmonary disease. Thorax. 2006;61(10):849-853.

26. Lomholt FK, Laulund AS, Bjarnason NH, Jorgensen HL, Godtfredsen NS. Meta-analysis of routine blood tests as predictors of mortality in COPD. Eur Clin Respir J. 2014;1.

27. Hu G, Wu Y, Zhou Y, Yu Y, Liang W, Ran P. Cystatin C as a predictor of in-hospital mortality after exacerbation of COPD. Respir Care. 2016;61(7):950-957.

28. Hu G, Zhou Y, Wu Y, Yu Y, Liang W, Ran P. The pneumonia severity index as a predictor of in-hospital mortality in acute exacerbation of chronic obstructive pulmonary disease. PLos One. 2015;10(7): e0133160.

29. Song YJ, Zhou ZH, Liu YK, Rao SM, Huang YJ. Prothrombotic state in senile patients with acute exacerbations of chronic obstructive pulmonary disease combined with respiratory failure. Exp Ther Med. 2013;5(4): 1184-1188.

30. Karami-Djurabi R, Klok FA, Kooiman J, Velthuis SI, Nijkeuter M, Huisman MV. D-dimer testing in patients with suspected pulmonary embolism and impaired renal function. Am J Med. 2009;122(11): 1050-1053.

31. Lindner G, Funk GC, Pfortmueller CA, et al. D-dimer to rule out pulmonary embolism in renal insufficiency. Am J Med. 2014;127(4): 343-347.

32. Jafri SM, Ozawa T, Mammen E, Levine TB, Johnson C, Goldstein S. Platelet function, thrombin and fibrinolytic activity in patients with heart failure. Eur Heart J. 1993;14(2):205-212.
International Journal of COPD

\section{Publish your work in this journal}

The International Journal of COPD is an international, peer-reviewed journal of therapeutics and pharmacology focusing on concise rapid reporting of clinical studies and reviews in COPD. Special focus is given to the pathophysiological processes underlying the disease, intervention programs, patient focused education, and self management protocols.

\section{Dovepress}

This journal is indexed on PubMed Central, MedLine and CAS. The manuscript management system is completely online and includes a very quick and fair peer-review system, which is all easy to use. Visit http://www.dovepress.com/testimonials.php to read real quotes from published authors. 